\title{
Pengaruh Proactive Personality dan Organizational Support for Career Development terhadap Career Success melalui Career Commitment yang Dimoderasi oleh Self-Efficacy (Studi pada PT Bogasari ISM Flour Mills Tbk. Surabaya)
}

\author{
Revan Jaya Kusuma \& Praptini Yulianti \\ Master of Science in Management Airlangga University, Surabaya, Indonesia \\ e-mail: revanjayakusuma93@gmail.com
}

\begin{abstract}
Career success is a way for individuals to fulfill their needs for achievement and effort during work, even career success is someone's goal in working. The sample in this study were 65 production department employees with quantitative analysis approaches. In this study using PLS (Partial Least Square) analysis with SmartPLS 3.0 software. Research on career success benefits both individuals and organizations. At the individual level, career success can be observed from the objective (extrinsic) and subjective (intrinsic). Knowledge of career success helps individuals develop the right strategies to commit to careers in their working days. At the organizational level, knowledge of the relationship between proactive personality and organizational support for career development towards career success can help companies to design effective career systems. Companies that want to get competent human resources must understand the factors that affect their employees' career success, one of these factors is self-efficacy. The self-efficacy variable in this study is positioned as a moderator that influences the relationship between career success and career commitment. The purpose of this paper is to develop conceptual models and propose hypotheses that connect proactive personality and organizational support for career development in career success through career commitment that is moderated by self-efficacy.
\end{abstract}

Keywords: proactive personality; organizational support for career development; career commitment; self-efficacy; career success

\section{PENDAHULUAN}

Salah satu tujuan seseorang bekerja adalah untuk mencapai kesuksesan karier pada perusahaannya, tidak sedikit dari mereka yang berupaya bekerja baik demi mendapatkan karier yang diinginkan karena karier sendiri merupakan keseluruhan jabatan atau posisi yang mungkin akan diduduki seseorang dalam organisasinya. Seibert, Crant, \& Kraimer (1999) mendefinisikan kesuksesan karier sebagai hasil dan pencapaian positif dari pengalaman kerja seseorang. Kesuksesan karier bisa diamati dari objektif (ekstrinsik) dan subjektif (intrinsik), kesuksesan karier objektif ini bisa diukur dan diamati secara langsung, namun berbeda dengan kesuksesan karier subjektif yang hanya bisa dirasakan oleh orang yang terlibat dalam kariernya sendiri.

PT Bogasari merupakan pabrik tepung terigu di Indonesia yang memiliki kapasitas produksi sebesar 3,6 juta ton per tahun, hal tersebut menjadikan PT Bogasari merupakan pabrik tepung terbesar di dunia dalam satu lokasi. Pabrik tepung terigu tersebut memiliki beberapa fasilitas yang supporting prosesnya produksi di antaranya milling, storage dan jetty. Informasi yang diberikan oleh PT Bogasari Surabaya melalui Corporate Profile dan PKB disebutkan bahwa PT Bogasari Surabaya sangat mendukung karyawannya untuk dapat mengembangkan kariernya untuk mendapatkan kepuasan karier karyawan 
(subjektif karier) maupun gaji yang diharapkan (objektif karier). Melalui wawancara dengan karyawan operator dari PT Bogasari Surabaya khususnya bagian produksi, mereka menjelaskan bahwa semua karyawan tetap perusahaan PT Bogasari Surabaya mempunyai kesempatan karier yang sama melalui penilaian kinerja minimal B dan penilaian yang diberikan tercantum pada PPK (penilaian prestasi kerja) tiap karyawan yang bisa dilihat di intranet perusahaan ini. Karyawan harus berinisiatif dan berinovasi selepas dari rutinitas job daily mereka untuk mendapatkan PPK dengan predikat nilai B.

Dalam penelitian ini akan membuktikan bahwa perusahaan mendukung karyawannya untuk mencapai karier yang diinginkan. Permasalahan dari penelitian yang dimaksud adalah, kesiapan karyawan dalam merencanakan karier mereka. Selain itu, peneliti mencoba memasukkan beberapa variabel yang dapat memengaruhi career success, seperti variabel Day \& Allen (2004) menyatakan bahwa orang yang berkepribadian proaktif dapat mengambil langkah aktif untuk menemukan peluang konkret di luar organisasi karena sifat proaktif pada dasarnya adalah aktif, orientasi perilaku terhadap lingkungan. (Hall, 1989) menyatakan bahwa organisasional support for career development dapat meningkatkan pertumbuhan karier seseorang atau perolehan kompetensi yang relevan untuk peran karier mereka, karena pertumbuhan karier ini dapat menjadi milik tujuan karier seseorang maupun realisasi tujuan komitmen karier mereka. (Hall, 1989) menyatakan bahwa komitmen karier didefinisikan sebagai sikap seseorang terhadap motivasi untuk peran karier mereka dalam bekerja. Day \& Allen (2004) menemukan selfefficacy terkait dengan indikator keberhasilan karier dan efektivitas kinerja. Karyawan yang menunjukkan self-efficacy karier yang tinggi akan meningkatkan komitmen mereka untuk mencapai keberhasilan karier yang sukses dibandingkan dengan mereka yang kurang berminat dan kurang berkomitmen.

Penelitian ini juga bertujuan untuk menganalisis apakah karyawan operator bagian produksi tersebut memiliki proactive personality sehingga mereka dapat menentukan kesuksesan kariernya. Dengan adanya organizational support for career development melalui program pengembangan kompetensi SDM diharapkan karyawan operator bagian produksi ini memiliki kepribadian yang aktif untuk terus berkembang dan berkontribusi untuk kemajuan perusahaan.

\section{KERANGKA TEORETIS}

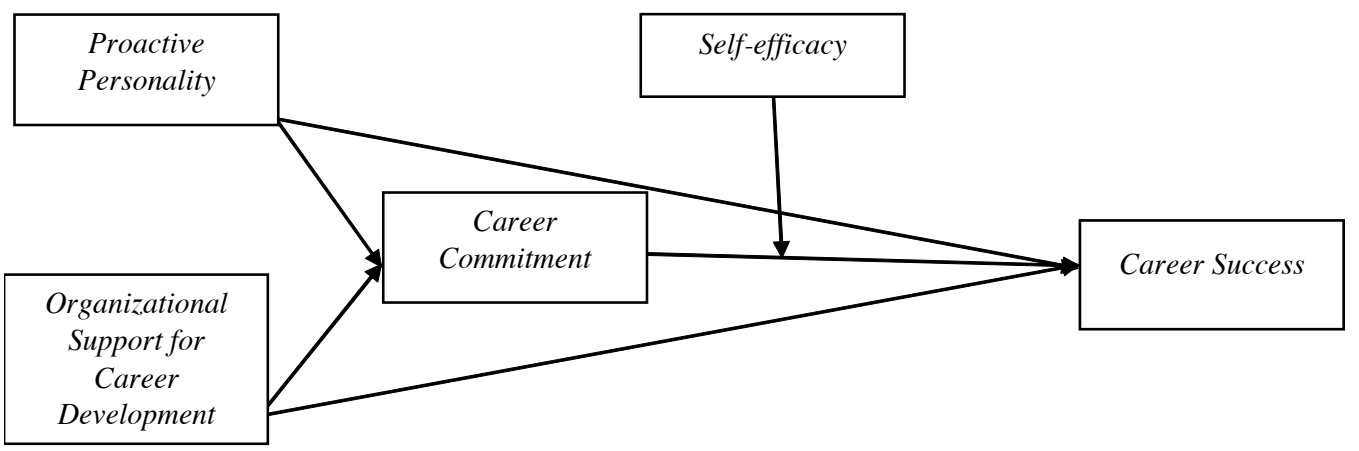

Sumber: data diolah dari penulis

Gambar 1 Model Analisis 


\section{Pengembangan Hipotesis}

Pengaruh Proactive Personality terhadap career success

Dalam penelitian yang telah dilakukan oleh (Seibert et al., 1999) menyebutkan bahwa pendekatan teoretis pada tingkat proaktif personality seseorang terhadap hasil karier yang objektif dan subjektif berasal dari psikologi interaksional. Peneliti menemukan adanya hubungan positif dan signifikan antara kepribadian proaktif dan kesuksesan karier.

H1: Proactive personality akan berpengaruh positif dan signifikan terhadap career success

Pengaruh Organizational support for career development (OSCD) terhadap career success

Pada penelitian (Kong, Cheung, \& Song, 2012) menjelaskan bahwa kegiatan manajemen karier yang efektif seperti training, mentoring, penilaian kinerja, dan program pengembangan karier terhadap karyawan mereka merupakan kegiatan yang bermanfaat untuk pengembangan kompetensi karier. Peneliti menemukan adanya hubungan positif dan signifikan antara Organizational support for career development dan kesuksesan karier.

H2: Organizational support for career development akan berpengaruh positif dan signifikan terhadap career success

Pengaruh proactive personality terhadap career commitment

Dalam penelitian yang dilakukan oleh (Bateman \& Crant, 1993) menjelaskan bahwa kepribadian proaktif adalah "disposisi pribadi terhadap perilaku proaktif”, individu proaktif menunjukkan inisiatif, secara aktif mencari peluang yang melayani tujuan mereka, dan bertahan dalam mengubah hal-hal dengan cara itu memajukan minat dan karier mereka. Peneliti menemukan adanya hubungan positif dan signifikan antara kepribadian proaktif dan kesuksesan karier.

H3: Proactive personality akan berpengaruh positif dan signifikan terhadap career commitment

Pengaruh organizational support for career development terhadap career commitment

Dalam penelitian yang dilakukan oleh (Colarelli \& Bishop, 1990) menyatakan bahwa komitmen karier adalah kepedulian praktis individu dan organisasi, dengan demikian sangat penting untuk pengembangan kemampuan karena komitmen karier membantu seorang individu untuk bertahan dalam jenis pekerjaan yang diberikan cukup lama untuk mengembangkan keterampilan khusus. Peneliti menemukan adanya hubungan positif dan signifikan antara organizational support for career development dan komitmen karier.

H4: Organizational support for career development akan berpengaruh positif dan signifikan terhadap career commitment

\section{Pengaruh career commitment terhadap career success}

Dalam penelitian (Colarelli \& Bishop, 1990) menyatakan bahwa komitmen karier telah menjadi sumber makna dan kesinambungan pekerjaan yang signifikan ketika organisasi menjadi lebih datar dan kurang mampu memberikan pekerjaan atau karier yang aman. Peneliti menemukan adanya hubungan positif dan signifikan antara karier komitmen dan karier sukses. 
H5: Career commitment akan berpengaruh positif dan signifikan terhadap career success

Pengaruh proactive personality terhadap career success yang dimediasi career commitment

Dalam penelitian (Bateman \& Crant, 1993) menyatakan bahwa kepribadian proaktif, atau disposisi pribadi terhadap proactive mencirikan orang-orang yang berusaha mengubah lingkungan dengan cara yang memajukan karier dan tujuan mereka (Seibert et al., 1999). Peneliti menemukan komitmen karier memediasi hubungan positif dan signifikan antara proactive personality dan career success.

H6: Proaktif personality akan berpengaruh positif dan signifikan terhadap career success melalui career commitment.

\section{Pengaruh organizational support for career deve-} lopment terhadap career success yang dimediasi career commitment

Dalam penelitian (Orpen \& Orpen, 2005) telah menemukan hubungan positif dalam hal pengalaman dengan kegiatan manajemen karier yang terpisah, seperti mentoring, dan berkaitan dengan pengalaman organisasi karier manajemen secara keseluruhan. Individu dengan komitmen karier yang kuat dan tingkat harapan karier yang lebih tinggi dapat membuat progress yang signifikan dalam karier mereka. Namun dalam penelitian ini career commitment diposisikan memediasi hubungan antara OSCD dengan career success.

H7: Organizational support for career development akan berpengaruh positif dan signifikan terhadap career success melalui career commitment.
Pengaruh career commitment terhadap career success yang dimoderasi oleh self-efficacy

Penelitian yang membahas career commitment dan self-efficacy sebelumnya telah dilakukan oleh (Ballout, 2009) menemukan bahwa self-efficacy sebagai variabel intervening memediasi hubungan antara komitmen karier dan subjective career success dan objective career success. Individu dengan self-efficacy tinggi keyakinan menetapkan tujuan karier yang lebih tinggi, lebih berupaya, dan mengejar strategi karier yang mengarah pada pencapaian tujuan tersebut. Peneliti menemukan self-efficacy memoderasi hubungan positif dan signifikan antara commitment career dan career success.

H8: career commitment akan berpengaruh positif dan signifikan terhadap career success yang dimoderasi oleh self efficacy

\section{METODE PENELITIAN}

Sesuai dengan kerangka konseptual yang sudah dibahas di bab sebelumnya, maka penelitian kali ini menggunakan suatu pendekatan kuantitatif yaitu penelitian yang menitikberatkan pada pengujian hasil hipotesis, penggunaan data yang sudah terukur, dan pengujian kausalitas sehingga mendapatkan kesimpulan secara umum. Pendekatan kuantitatif ini menggunakan (alat analisis) statistik.

\section{Populasi dan Sampel Penelitian}

Populasi pada penelitian ini merupakan karyawan tetap PT Bogasari Surabaya dengan kriteria yaitu mempunyai masa kerja lebih dari 2 tahun dengan jabatan operator. Dengan kriteria tersebut maka, jumlah populasi yang di dapatkan sebanyak 65 orang. Oleh karena jumlah populasi 65 orang karyawan maka jumlah tersebut dija- 
dikan sebagai responden kayawan PT Bogasari Surabaya. Teknik untuk menentukan sampel yang akan digunakan dalam penelitian ini adalah non probability sampling dengan teknik sampling jenuh atau bisa di namakan teknik sensus, yang dapat diartikan bahwa semua anggota populasi dijadikan sampel.

\section{Metode Pengumpulan Data}

Data yang digunakan dalam penelitian ini yaitu data primer yang diperoleh dengan menggunakan metode kuesioner yang dikirim kepada karyawan operator bagian produksi sebanyak 65 orang dalam waktu 2 minggu. Kuesioner juga dilengkapi dengan pertanyaan mengenai data demografi responden. Skala pengukuran pada penelitian ini menggunakan skala Likert yang terbagi dalam lima kategori jawaban. Masing-masing jawaban diberi skor antara satu sampai lima dengan parameter mulai dari sangat tidak setuju, tidak setuju, ragu-ragu, setuju dan sangat setuju.

\section{Definisi dan Pengukuran variabel}

Proactive personality dapat didefinisikan sebagai karyawan yang dapat mengenali peluang dan mereka dapat memengaruhi perubahan lingkungan di PT Bogasari Surabaya. Proactive personality diukur dengan menggunakan lima item pertanyaan yang diperoleh dari (Bateman \& Crant, 1993) dengan menyesuaikan objek penelitian. Ada tiga aspek proactive personality yang diukur yaitu proactive disposition, prototypic proactive personality, perspektif interaksionis. Masing-masing aspek tersebut terdapat item pertanyaan.

Organizational support for career development dapat didefinisikan dukungan yang diberikan oleh suatu organisasi untuk meningkatkan kesuksesan karier karyawan mereka seperti pelatihan, mentoring terhadap penilaian kinerja karyawan PT Bogasari Surabaya. organizational support for career development diukur dengan menggunakan 5 item pertanyaan yang diperoleh dari (Sturges, Guest, Conway, \& Mackenzie Davey, 2002)dengan menyesuaikan objek penelitian. Ada dua aspek organizational support for career development yang diukur yaitu secara formal dan informal.

Career commitment dapat didefinisikan sebagai sikap karyawan bagian produksi terhadap pekerjaan yang diinginkan. Career commitment diukur dengan menggunakan empat item pertanyaan yang diperoleh dari (Blau, 1988) dengan menyesuaikan objek penelitian. Ada dua aspek career commitment yang diukur yaitu occupational commitment dan career orientation. Masing-masing aspek tersebut terdapat dua item pertanyaan.

Self-efficacy dapat diartikan sebagai suatu keyakinan diri karyawan terhadap kemampuan dirinya untuk melakukan dan menyelesaikan suatu masalah maupun tugas dari PT Bogasari Surabaya. Self-efficacy diukur dengan menggunakan enam item pertanyaan yang diperoleh dari (Bandura, 1997) dengan menyesuaikan objek penelitian. Ada tiga aspek self-efficacy yang diukur yaitu magnitude, strength, dan generality. Masing-masing aspek tersebut terdapat dua item pertanyaan.

Career success dapat didefinisikan sebagai pencapaian positif yang dihasilkan oleh karyawan PT Bogasari berdasarkan pengalaman kerjanya. Career success diukur dengan menggunakan delapan item pertanyaan yang diperoleh dari (Judge, Higgins, Thoresen, \& Barrick, 1999)dengan menyesuaikan objek penelitian. Ada dua aspek atau dimensi career success yang diukur yaitu subjective career dan objective career. Masing- 
masing aspek tersebut terdapat empat item pertanyaan.

\section{Metode dan Teknik Analisis}

Setelah memperoleh data yang dibutuhkan melalui kuesioner dan pengumpulan data melalui data primer, maka selanjutnya adalah melakukan analisis dengan alat uji statistik untuk menjawab hipotesis penelitian. Analisis data merupakan proses pengolahan dan penyederhanaan data ke dalam bentuk yang lebih mudah dibaca dan diinterpretasikan. Penelitian ini menggunakan analisis PLS (Partial Least Square) dengan software SmartPLs 3.0.

\section{ANALISIS DAN PEMBAHASAN}

\section{Karakteristik Responden}

Secara umum, responden pada penelitian ini berjenis kelamin laki-laki semua, usia responden yang paling banyak adalah berumur 4150 tahun sebanyak 22 orang atau dengan persentase $33.8 \%$, pendidikan terakhir responden terbanyak yaitu SMA/SMK sebanyak 45 orang

Tabel 1

Hasil Uji Validitas Masing-Masing Indikator (Sebelum Drop Indikator)

\begin{tabular}{|c|c|c|c|c|c|c|}
\hline Indikator & $\begin{array}{c}\text { Proactive } \\
\text { Personality } \\
\text { (PP) } \\
\end{array}$ & OSCD & $\begin{array}{c}\text { Career } \\
\text { Commitment } \\
\text { (CC) }\end{array}$ & $\begin{array}{c}\text { Self- } \\
\text { Efficacy } \\
\text { (SE) }\end{array}$ & $\begin{array}{c}\text { Career } \\
\text { Success } \\
\text { (CS) }\end{array}$ & $\begin{array}{c}\text { Valid/ Tidak } \\
\text { Valid }\end{array}$ \\
\hline $\mathrm{X} 1.1$ & 0.651 & & & & & Valid \\
\hline $\mathrm{X} 1.2$ & 0.757 & & & & & Valid \\
\hline $\mathrm{X} 1.3$ & 0.681 & & & & & Valid \\
\hline X1.4 & 0.504 & & & & & Tidak Valid \\
\hline $\mathrm{X} 1.5$ & 0.795 & & & & & Valid \\
\hline $\mathrm{X} 2.1$ & & 0.456 & & & & Tidak Valid \\
\hline $\mathrm{X} 2.2$ & & 0.718 & & & & Valid \\
\hline $\mathrm{X} 2.3$ & & 0.751 & & & & Valid \\
\hline $\mathrm{X} 2.4$ & & 0.631 & & & & Valid \\
\hline $\mathrm{X} 2.5$ & & 0.715 & & & & Valid \\
\hline Z1.1 & & & 0.694 & & & Valid \\
\hline Z1.2 & & & 0.862 & & & Valid \\
\hline Z1.3 & & & 0.836 & & & Valid \\
\hline Z1.4 & & & 0.565 & & & Tidak Valid \\
\hline $\mathrm{Z} 2.1$ & & & & 0.725 & & Valid \\
\hline $\mathrm{Z} 2.2$ & & & & 0.692 & & Valid \\
\hline Z2.3 & & & & 0.065 & & Tidak Valid \\
\hline Z2.4 & & & & 0.010 & & Tidak Valid \\
\hline $\mathrm{Z} 2.5$ & & & & 0.727 & & Valid \\
\hline Z2.6 & & & & 0.725 & & Valid \\
\hline Y1.1 & & & & & 0.825 & Valid \\
\hline $\mathrm{Y} 1.2$ & & & & & 0.646 & Valid \\
\hline Y1.3 & & & & & 0.461 & Tidak Valid \\
\hline Y1.4 & & & & & 0.668 & Valid \\
\hline Y1.5 & & & & & 0.690 & Valid \\
\hline Y1.6 & & & & & 0.694 & Valid \\
\hline Y1.7 & & & & & 0.791 & Valid \\
\hline $\mathrm{Y} 1.8$ & & & & & 0.706 & Valid \\
\hline
\end{tabular}

Sumber: Hasil pengolahan data primer dengan smartPLS 
atau sebesar 69.2\%, masa kerja responden terbanyak adalah masa kerja 11-15 tahun sebanyak 24 orang atau dengan persentase $36.9 \%$ dari jumlah keseluruhan yaitu 65 orang.

\section{Analisis Hasil PLS}

Bagian model dan pengujian hipotesis terdiri dari dua bagian, yaitu evaluasi outer model dan inner model. Sesuai dengan teknik PLS (partial leas square), evaluasi outer model dilakukan untuk mengetahui validitas dan reabilitas instrumen pengukuran, sedangkan evaluasi inner model dilakukan untuk mengetahui suatu hubungan kausalitas antar variabel pada penelitian ini.

Rule of thumb yang digunakan untuk melihat nilai loading factor yang dianggap valid adalah 0,6. Pada Tabel 2 menunjukkan hasil uji validasi untuk masing-masing indikator (sebelum drop indikator).

\section{Hasil Uji Validitas Masing-Masing Indikator (Sebelum Drop Indikator)}

Terdapat enam faktor yang mempunyai nilai $<0.6$ dan indikator tersebut dinyatakan tidak valid yaitu pada indikator X1.4, X2.1, Z1.4, Z2.3, Z2.4 dan Y1.3. Oleh karena itu, enam indikator yang tidak valid ini yaitu X1.4, X2.1, Z1.4, Z2.3, Z2.4 dan Y1.3 dihapus oleh peneliti.

Berikut adalah Tabel 4.2 yang menunjukkan hasil uji validitas untuk masing-masing indikator setelah dilakukan drop indikator atau penghapusan indikator yang tidak valid, hasilnya sebagai berikut.

Tabel 2

Hasil Uji Validitas Masing-Masing Indikator (Setelah Drop Indikator)

\begin{tabular}{|c|c|c|c|c|c|c|}
\hline Indikator & $\begin{array}{l}\text { Proactive } \\
\text { Personality } \\
\text { (PP) } \\
\end{array}$ & OSCD & $\begin{array}{c}\text { Career } \\
\text { Commitment } \\
(\mathrm{CC})\end{array}$ & $\begin{array}{c}\text { Self-Efficacy } \\
\text { (SE) }\end{array}$ & $\begin{array}{c}\text { Career } \\
\text { Success } \\
\text { (CS) }\end{array}$ & $\begin{array}{c}\text { Valid/ } \\
\text { Tidak Valid }\end{array}$ \\
\hline $\mathrm{X} 1.1$ & 0.687 & & & & & Valid \\
\hline $\mathrm{X} 1.2$ & 0.821 & & & & & Valid \\
\hline $\mathrm{X} 1.3$ & 0.696 & & & & & Valid \\
\hline X1.5 & 0.827 & & & & & Valid \\
\hline $\mathrm{X} 2.2$ & & 0.706 & & & & Valid \\
\hline $\mathrm{X} 2.3$ & & 0.752 & & & & Valid \\
\hline $\mathrm{X} 2.4$ & & 0.633 & & & & Valid \\
\hline X2.5 & & 0.735 & & & & Valid \\
\hline Z1.1 & & & 0.734 & & & Valid \\
\hline $\mathrm{Z} 1.2$ & & & 0.880 & & & Valid \\
\hline Z1.3 & & & 0.816 & & & Valid \\
\hline $\mathrm{Z} 2.1$ & & & & 0.730 & & Valid \\
\hline $\mathrm{Z} 2.2$ & & & & 0.713 & & Valid \\
\hline$\overline{Z 2.5}$ & & & & 0.715 & & Valid \\
\hline Z2.6 & & & & 0.723 & & Valid \\
\hline Y1.1 & & & & & 0.827 & Valid \\
\hline Y1.2 & & & & & 0.635 & Valid \\
\hline Y1.4 & & & & & 0.655 & Valid \\
\hline Y1.5 & & & & & 0.682 & Valid \\
\hline Y1.6 & & & & & 0.706 & Valid \\
\hline Y1.7 & & & & & 0.814 & Valid \\
\hline Y1.8 & & & & & 0.713 & Valid \\
\hline
\end{tabular}

Sumber: Hasil pengolahan data primer dengan smartPLS 
Tabel 3 Hasil Cross Loading Hasil Penelitian

\begin{tabular}{|c|c|c|c|c|c|}
\hline Indikator & $\begin{array}{c}\text { Proactive } \\
\text { Personality } \\
\text { (PP) }\end{array}$ & OSCD & $\begin{array}{c}\text { Career } \\
\text { Commitment } \\
\text { (CC) }\end{array}$ & $\begin{array}{c}\text { Self-Efficacy } \\
\text { (SE) }\end{array}$ & $\begin{array}{c}\text { Career } \\
\text { Success } \\
\text { (CS) }\end{array}$ \\
\hline $\mathrm{X} 1.1$ & $\mathbf{0 . 6 8 7}$ & 0.217 & 0.162 & 0.221 & 0.243 \\
\hline $\mathrm{X} 1.2$ & $\mathbf{0 . 8 2 1}$ & 0.163 & 0.221 & 0.281 & 0.320 \\
\hline $\mathrm{X} 1.3$ & $\mathbf{0 . 6 9 6}$ & 0.257 & 0.218 & 0.329 & 0.326 \\
\hline $\begin{array}{c}\text { Indikato } \\
\text { r }\end{array}$ & $\begin{array}{c}\text { Proactive } \\
\text { Personality } \\
\text { (PP) }\end{array}$ & OSCD & $\begin{array}{c}\text { Career } \\
\text { Commitment } \\
\text { (CC) }\end{array}$ & $\begin{array}{c}\text { Self-Efficacy } \\
\text { (SE) }\end{array}$ & $\begin{array}{c}\text { Career } \\
\text { Success } \\
\text { (CS) }\end{array}$ \\
\hline $\mathrm{X} 1.5$ & $\mathbf{0 . 8 2 7}$ & 0.460 & 0.321 & 0.460 & 0.432 \\
\hline $\mathrm{X} 2.2$ & 0.379 & $\mathbf{0 . 7 0 6}$ & 0.292 & 0.427 & 0.397 \\
\hline $\mathrm{X} 2.3$ & 0.421 & $\mathbf{0 . 7 5 2}$ & 0.353 & 0.430 & 0.456 \\
\hline $\mathrm{X} 2.4$ & 0.112 & $\mathbf{0 . 6 3 3}$ & 0.394 & 0.233 & 0.402 \\
\hline $\mathrm{X} 2.5$ & 0.243 & $\mathbf{0 . 7 3 5}$ & 0.516 & 0.576 & 0.682 \\
\hline $\mathrm{Z} 1.1$ & 0.563 & 0.578 & $\mathbf{0 . 7 3 4}$ & 0.528 & 0.627 \\
\hline $\mathrm{Z} 1.2$ & 0.407 & 0.438 & $\mathbf{0 . 8 8 0}$ & 0.355 & 0.441 \\
\hline $\mathrm{Z} 1.3$ & 0.387 & 0.537 & $\mathbf{0 . 8 1 6}$ & 0.645 & 0.432 \\
\hline $\mathrm{Z} 2.1$ & 0.243 & 0.576 & 0.516 & $\mathbf{0 . 7 3 0}$ & 0.682 \\
\hline $\mathrm{Z} 2.2$ & 0.366 & 0.337 & 0.556 & $\mathbf{0 . 7 1 3}$ & 0.506 \\
\hline $\mathrm{Z} 2.5$ & 0.250 & 0.572 & 0.680 & $\mathbf{0 . 7 1 5}$ & 0.614 \\
\hline $\mathrm{Z} 2.6$ & 0.192 & 0.465 & 0.616 & $\mathbf{0 . 7 2 3}$ & 0.513 \\
\hline $\mathrm{Y} 1.1$ & 0.366 & 0.337 & 0.734 & 0.586 & $\mathbf{0 . 8 2 7}$ \\
\hline $\mathrm{Y} 1.2$ & 0.250 & 0.572 & 0.580 & 0.440 & $\mathbf{0 . 6 3 5}$ \\
\hline $\mathrm{Y} 1.4$ & 0.192 & 0.465 & 0.516 & 0.514 & $\mathbf{0 . 6 5 5}$ \\
\hline $\mathrm{Y} 1.5$ & 0.076 & 0.303 & 0.477 & 0.630 & $\mathbf{0 . 6 8 2}$ \\
\hline $\mathrm{Y} 1.6$ & 0.139 & 0.261 & 0.482 & 0.513 & $\mathbf{0 . 7 0 6}$ \\
\hline $\mathrm{Y} 1.7$ & 0.520 & 0.663 & 0.378 & 0.615 & $\mathbf{0 . 8 1 4}$ \\
\hline $\mathrm{Y} 1.8$ & 0.497 & 0.482 & 0.466 & 0.523 & $\mathbf{0 . 7 1 3}$ \\
\hline & & & & & \\
\hline
\end{tabular}

Sumber: Hasil pengolahan data primer dengan smartPLS

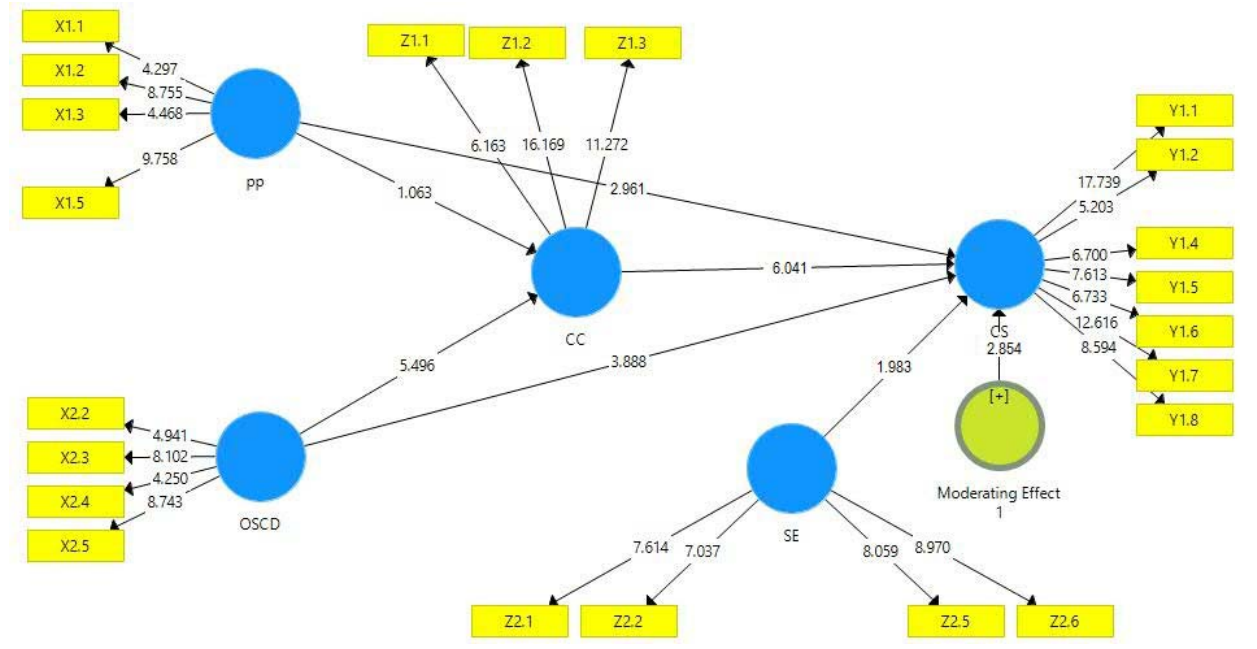

Sumber: Hasil pengolahan data primer dengan SmartPLS

Gambar 2 Model Penelitian Hasil Bootstrapping SmartPLS 
Berdasarkan dari Tabel 2 diketahui bahwa terdapat enam indikator yang tidak valid dan sudah dihapus sehingga semua loading factor mempunyai nilai $>0.6$ atau dinyatakan valid dan dapat digunakan untuk mengukur konstruk dalam penelitian. Pada tabel skor loading akan terlihat bahwa masing-masing indikator di suatu konstruk akan berbeda dengan indikator di konstruk lain dan mengumpul pada konstruk yang dimaksud. Hasil dari validitas diskriminan dapat dilihat pada Tabel 3 .

Berdasarkan dari Tabel 4.3 nilai pada cross loading tersebut dapat diketahui bahwa secara umum indikator yang menyusun variabel dalam penelitian ini telah memenuhi discriminant validity. Gambar 2 menunjukkan model penelitian bootstrapping dengan smartPLS 3.0.

Pada Tabel 4 menunjukkan nilai AVE pada masing-masing variabel, kemudian dibandingkan dengan nilai akar AVE, apabila nilai AVE $>0.50$ maka variabel tersebut dinyatakan valid.

Tabel 4 Hasil Uji AVE

\begin{tabular}{|l|c|c|c|}
\hline Variabel & AVE & $\begin{array}{c}\text { Nilai } \\
\text { Cut Off }\end{array}$ & $\begin{array}{c}\text { Valid/ } \\
\text { Tidak Valid }\end{array}$ \\
\hline PP & 0.546 & \multirow{5}{*}{$>0.5$} & Valid \\
\cline { 1 - 1 } OSCD & 0.501 & Valid \\
\cline { 1 - 1 } CC & 0.660 & Valid \\
\hline SE & 0.519 & Valid \\
\hline CS & 0.522 & & Valid \\
\hline
\end{tabular}

Sumber: Hasil pengolahan data primer dengan smartPLS

Berdasarkan nilai AVE yang ditunjukkan oleh Tabel 4 diketahui bahwa nilai AVE untuk setiap variabel laten memiliki nilai $>0.50$, artinya adalah nilai AVE memiliki validitas diskriminan yang cukup. Setelah mengetahui nilai AVE, langkah selanjutnya adalah menghitung nilai akar AVE dan membandingkannya dengan korelasi antar variabel laten pada model penelitian.

Validitas diskriminan yang baik ditunjukkan dari akar kuadrat AVE untuk tiap konstruk lebih besar dari korelasi antar konstruk dalam model. Nilai kuadrat AVE akan disajikan pada Tabel 5 .

Tabel 5 Hasil Uji Fornell-Lareker Criterion (Akar Kuadrat AVE)

\begin{tabular}{|l|c|c|c|c|c|}
\hline & CC & CS & OSCD & SE & PP \\
\hline CC & $\mathbf{0 . 8 1 2}$ & & & & \\
\hline CS & 0.619 & $\mathbf{0 . 7 2 2}$ & & & \\
\hline OSCD & 0.572 & 0.618 & $\mathbf{0 . 7 0 8}$ & & \\
\hline SE & 0.623 & 0.714 & 0.614 & $\mathbf{0 . 7 2 0}$ & \\
\hline PP & 0.327 & 0.464 & 0.397 & 0.460 & $\mathbf{0 . 7 3 9}$ \\
\hline
\end{tabular}

Sumber: Hasil pengolahan data primer dengan smartPLS

Berdasarkan Tabel 5 dapat diketahui bahwa nilai akar kuadrat AVE setiap variabel laten lebih besar bila dibandingkan korelasi dengan variabel lainnya. Hal ini mengindikasikan bahwa variabel laten tersebut memiliki indikator dengan validitas diskriminan yang baik.

Rule of thumb yang digunakan untuk menilai rabilitas konstruk yaitu nilai composite reability harus lebih besar dari 0.7 (>0.7), sedangkan untuk nilai Cronbach's Alpha adalah $>0.7$ (Ghozali, 2012). Hasilnya akan terlihat pada Tabel 6.

Tabel 6

Hasil Uji Composite Reliability dan Cronbach’s Alpha

\begin{tabular}{|l|c|c|c|c|}
\hline & $\begin{array}{c}\text { Composite } \\
\text { Reliability }\end{array}$ & $\begin{array}{c}\text { Cronbach's } \\
\text { Alpha }\end{array}$ & $\begin{array}{c}\text { Nilai } \\
\text { Cut Off }\end{array}$ & $\begin{array}{c}\text { Reliebel/ } \\
\text { Tidak Reliebel }\end{array}$ \\
\hline PP & 0.825 & 0.750 & & Reliebel \\
\hline OSCD & 0.800 & 0.719 & \multirow{5}{*}{$>0.7$} & Reliebel \\
\hline CC & 0.853 & 0.755 & Reliebel \\
\hline SE & 0.812 & 0.715 & & Reliebel \\
\hline CS & 0.883 & 0.859 & & Reliebel \\
\hline
\end{tabular}

Sumber: Hasil pengolahan data primer dengan smartPLS

Berdasarkan nilai Tabel 6 menunjukkan bahwa semua nilai variabel laten melalui uji reabilitas memenuhi persyaratan rule of thumb yaitu $>0.7$. Hasil nilai dari uji reabilitas ini mengindikasikan bahwa semua variabel adalah reliable dan dapat digunakan dalam penelitian. 


\section{Analisis Model Struktural}

Dalam menganalisis model struktural pada analisis smartPLS menggunakan nilai $\mathrm{R}$-square pada variabel dependen, dan juga nilai koefisien path atau T-values tiap path untuk uji signifikansi antarkonstruk dalam model struktural. Nilai RSquare tersebut digunakan untuk mengukur tingkat variasi perubahan variabel independen terhadap dependen. Hasil uji R-square akan terlihat pada Tabel 7.

Tabel 7 Hasil Uji R-Squares

\begin{tabular}{|c|c|c|c|}
\hline & R-Square & Nilai Cut Off & Keterangan \\
\hline PP & - & \multirow{5}{*}{$\begin{array}{c}\text { Kuat }>0.67> \\
\text { Moderate }>0.33> \\
\text { Lemah }>0.19\end{array}$} & - \\
\hline OSCD & - & & - \\
\hline CC & 0.339 & & Moderate \\
\hline SE & - & & - \\
\hline $\mathrm{CS}$ & 0.917 & & Kuat \\
\hline
\end{tabular}

Sumber: Hasil pengolahan data primer dengan smartPLS

Berdasarkan hasil R-Square yang telah diketahui dari Tabel 7 maka dapat dijelaskan bahwa nilai R-Square sebesar 0.339 untuk variabel career commitment yang berarti bahwa pengaruh terhadap career commitment yang dapat dijelaskan oleh proactive personality dan OSCD adalah sebesar 34 persen (34\%) sedangkan sisanya dijelaskan oleh variabel lain di luar model yang diukur. Kemudian nilai R-Square sebesar
0.917 untuk variabel career success yang berarti bahwa pengaruh terhadap career success yang dapat dijelaskan oleh proactive personality dan OSCD adalah sebesar 92 persen (92\%) sedangkan sisanya dijelaskan oleh variabel lain di luar model yang diukur.

\section{Pengujian Hipotesis}

Jika nilai T-statistic lebih dari 1.96 untuk signifikansi lima persen (5\%) maka terdapat pengaruh antar variabel dan hipotesis diterima, jika kurang dari 1.96 maka hipotesis ditolak. Hasil uji hipotesis tersebut dapat dilihat pada Tabel 8.

Berdasarkan hasil pada uji hipotesis Tabel 8 menunjukkan hasil lima hipotesis diterima dan satu hipotesis ditolak, penjelasannya adalah sebagai berikut.

Hasil perhitungan dengan menggunakan smartPLS 3.0 menunjukkan nilai path coefficients variabel proactive personality terhadap career success memiliki pengaruh dengan nilai koefisien beta 0.209 dan nilai T-statistic 2.961 yang artinya signifikan karena nilai T-statistic lebih dari 1.96. Artinya adalah hipotesis 1 terdukung. OSCD terhadap career success memiliki pengaruh dengan nilai koefisien beta 0.219 dan nilai T-statistic 3.888 yang artinya signifikan karena nilai T-Statistic

Tabel 8 Hasil Uji Hipotesis

\begin{tabular}{|c|c|c|c|c|c|c|c|}
\hline Hipotesis & $\begin{array}{c}\text { Pengaruh } \\
\text { Antar- } \\
\text { Variabel }\end{array}$ & $\begin{array}{c}\text { Original } \\
\text { Sampel }\end{array}$ & $\begin{array}{c}\text { Sampel } \\
\text { Mean }\end{array}$ & $\begin{array}{c}\text { Standard } \\
\text { Deviation }\end{array}$ & T-Statistics & $\begin{array}{c}\text { Diterima/ } \\
\text { Ditolak }\end{array}$ & $\begin{array}{c}\text { Signifikan/ } \\
\text { Tidak } \\
\text { Signifikan }\end{array}$ \\
\hline H5 & CC-> CS & 0.695 & 0.683 & 0.063 & 6.041 & Diterima & Signifikan \\
\hline H4 & OSCD -> CC & 0.525 & 0.539 & 0.096 & 5.496 & Diterima & Signifikan \\
\hline H2 & OSCD -> CS & 0.219 & 0.218 & 0.056 & 3.888 & Diterima & Signifikan \\
\hline H8 & $\begin{array}{c}\text { Moderating } \\
\text { Effect 1 -> CS }\end{array}$ & 0.203 & 0.210 & 0.055 & 2.854 & Diterima & Signifikan \\
\hline H3 & PP -> CC & 0.119 & 0.113 & 0.011 & 1.063 & Ditolak & $\begin{array}{c}\text { Tidak } \\
\text { Signifikan }\end{array}$ \\
\hline H1 & PP -> CS & 0.209 & 0.205 & 0.056 & 2.961 & Diterima & Signifikan \\
\hline
\end{tabular}

Sumber: Hasil pengolahan data primer dengan smartPLS 
lebih dari 1.96. Artinya adalah hipotesis 2 terdukung. Proactive personality terhadap career commitment memiliki pengaruh dengan nilai koefisien beta 0.119 dan nilai T-Statistic 1.063 yang artinya tidak signifikan karena nilai T-Statistic kurang dari 1.96. Artinya adalah hipotesis 3 tidak terdukung. OSCD terhadap Career Commitment memiliki pengaruh dengan nilai koefisien beta 0.525 dan nilai T-Statistic 5.496 yang artinya signifikan karena nilai T-Statistic lebih dari 1.96. Artinya adalah hipotesis 4 terdukung. Career commitment terhadap career success memiliki pengaruh dengan nilai koefisien beta 0.695 dan nilai T-Statistic 6.041 yang artinya signifikan Karena nilai T-Statistic lebih dari 1.96. Artinya adalah hipotesis 5 terdukung. Self-Efficacy memoderasi hubungan antara career commitment terhadap Career Success memiliki pengaruh dengan nilai koefisien beta 0.203 dan nilai T-Statistic 2.854 yang artinya signifikan Karena nilai T-Statistic lebih dari 1.96. Artinya adalah hipotesis 8 terdukung.

Pada Tabel 9 Hasil uji specific indirect effects ditemukan terdapat pengaruh yang tidak signifikan pada pengaruh antara proactive personality terhadap career commitment, maka dapat disimpulkan bahwa career commitment tidak memediasi hubungan antara proactive personality terhadap Career Success (Hipotesis 6 ditolak). Selanjutnya, terdapat hubungan yang signifikan antara OSCD terhadap career com- mitment dan juga pada career commitment terhadap career success. Maka dapat disimpulkan bahwa career commitment memediasi hubungan antara OSCD terhadap career success (Hipotesis 7 diterima).

\section{PEMBAHASAN}

Pengaruh Proactive Personality terhadap $\mathrm{Ca}$ reer Success

Berdasarkan hasil pada pengujian hipotesis pertama menunjukkan hasil bahwa adanya pengaruh signifikan antara proactive personality terhadap career success, sehingga hipotesis pertama dapat diterima. Penelitian ini mendukung penelitian Scott E. Seibert and J. Michael Crant (1999) bahwa karyawan dengan kepribadian yang proaktif memiliki kesuksesan karier yang baik dalam perusahaan. Jika dikaitkan dengan perusahaan PT Bogasari Surabaya, maka karyawan yang memiliki kepribadian proaktif yang tinggi akan terdorong membuat suatu perbedaan di organisasinya untuk mencapai kesuksesan pada kariernya.

\section{Pengaruh OSCD terhadap Career Success}

Berdasarkan hasil pada pengujian hipotesis kedua menunjukkan hasil bahwa adanya penga-

Tabel 9 Hasil Specific Indirect Effects untuk Variabel Mediasi

\begin{tabular}{|c|c|l|l|l|l|l|l|}
\hline Hipotesis & $\begin{array}{c}\text { Hipotesis } \\
\text { Pengaruh } \\
\text { Antar- } \\
\text { Variabel }\end{array}$ & $\begin{array}{c}\text { Original } \\
\text { Sampel }\end{array}$ & $\begin{array}{c}\text { Sampel } \\
\text { Mean }\end{array}$ & $\begin{array}{c}\text { Standard } \\
\text { Deviation }\end{array}$ & T-Statistics & P-Value & $\begin{array}{l}\text { Signifikan/ } \\
\text { Tidak } \\
\text { Signifikan }\end{array}$ \\
\hline H7 & $\begin{array}{l}\text { OSCD -> } \\
\text { CC -> CS }\end{array}$ & 0.365 & 0.369 & 0.062 & 5.842 & 0.000 & Signifikan \\
\hline H6 & $\begin{array}{l}\text { PP-> CC } \\
->\text { CS }\end{array}$ & 0.082 & 0.094 & 0.079 & 1.044 & 0.297 & $\begin{array}{l}\text { Tidak } \\
\text { Signifikan }\end{array}$ \\
\hline
\end{tabular}

Sumber: Hasil pengolahan data primer dengan smartPLS 
ruh signifikan antara OSCD terhadap career success, sehingga hipotesis kedua dapat diterima. Penelitian ini mendukung penelitian (Orpen \& Orpen, 2005)yang menyatakan bahwa karyawan yang merasakan organizational support for career development dan juga merasakan kesempatan berkarier dapat berdampak pada kesuksesan karier mereka. Berdasarkan data di atas dapat dikatakan bahwa perusahaan PT Bogasari Surabaya menyadari untuk mendukung perkembangan usaha dan menjaga kesinambungan sukses perusahaan, perusahaan harus memiliki SDM yang andal, inovatif dan berdedikasi tinggi. Untuk memiliki SDM yang demikian, salah satunya memberikan opportunity pada karyawan operator bagian produksi tersebut untuk mengembangkan pengetahuan, keterampilan, dan perilaku yang baik dengan memberikan pelatihan berupa training.

\section{Pengaruh Proactive Personality terhadap Career Commitment}

Hasil uji hipotesis ketiga menunjukkan bahwa proactive personality tidak terbukti memiliki hubungan yang signifikan terhadap career commitment. Hasil penelitian ini tidak sesuai dengan penelitian (Arora \& Rangnekar, 2016) yang menjelaskan bahwa proactive personality memiliki pengaruh positif yang signifikan terhadap career commitment. Perbedaan tersebut dapat dipicu pada konteks penelitian dan karakteristik responden yang berbeda. Penelitian yang dilakukan (Arora \& Rangnekar, 2016) ditujukan pada responden di India utara pada karyawan manajerial dari kedua organisasi yaitu publik dan organisasi swasta, sedangkan penelitian ini dilakukan pada karyawan operator bagian produksi perusahaan PT Bogasari Indonesia. Jika dikaitkan dengan karakteristik responden berdasarkan usia dan masa kerja maka mayoritas responden pada penelitian ini berusia 41-50 tahun sebanyak 22 responden dengan persentase $33.8 \%$ dan memiliki masa kerja 11-15 tahun sebanyak 24 responden dengan persentase $36.9 \%$. Hal ini menunjukkan bahwa karyawan operator bagian produksi ini sudah mendekati masa pensiun sedangkan karier yang mereka dapat sampai saat ini masih operator dengan masa kerja yang dibilang bisa cukup lama namun tidak berpengaruh pada kariernya, hal tersebut akhirnya membuat mereka tidak berkomitmen dengan kariernya lagi.

\section{Pengaruh OSCD terhadap Career Commitment}

Berdasarkan hasil pada pengujian hipotesis keempat menunjukkan hasil adanya pengaruh signifikan antara OSCD terhadap career commitment, sehingga hipotesis keempat dapat diterima. Penelitian ini mendukung penelitian (Hall, 1989) menyatakan bahwa organizational support for career development berpengaruh positif yang signifikan terhadap career commitment. Berdasarkan hal tersebut dapat dikatakan bahwa perusahaan PT Bogasari Surabaya mendukung karyawan operator bagian produksi untuk mengembangkan pengetahuan dan keterampilan terkait dengan pekerjaan yang dilakukan dengan memberikan pelatihan berupa training.

\section{Pengaruh Career Commitment terhadap Career Success}

Berdasarkan hasil pada pengujian hipotesis kelima menunjukkan hasil adanya pengaruh signifikan antara career commitment terhadap career success dapat diterima. Penelitian ini mendukung penelitian (Ballout, 2009) menyatakan bahwa career commitment berpengaruh positif yang signifikan terhadap career success. Berdasarkan data di atas dapat dikatakan bahwa karyawan 
operator bagian produksi berkeinginan untuk bertahan di pekerjaannya dan bersedia menghabiskan banyak waktu untuk mengembangkan keterampilan pada karier di pekerjaannya.

\section{Pengaruh Proactive Personality terhadap Career} Success yang Dimediasi Career Commitment

Berdasarkan hasil pengujian hipotesis keenam menunjukkan hasil bahwa terdapat hubungan positif namun tidak signifikan antara proactive personality terhadap career success yang dimediasi oleh career commitment. Hasil penelitian ini tidak sesuai dengan penelitian (Seibert et al., 1999) bahwa karyawan yang memiliki kepribadian proaktif lebih cenderung terlibat dalam komitmen yang berorientasi pada karier karena fokus mereka dalam mencari peluang yang terkait dengan keberhasilan kariernya. Perbedaan ini dapat dipicu pada konteks penelitian dan karakteristik responden yang berbeda. Penelitian yang dilakukan (Seibert et al., 1999) ditujukan pada responden para alumni di western university, sedangkan penelitian ini dilakukan pada karyawan operator bagian produksi perusahaan PT Bogasari Indonesia. Perbedaan hasil ini dapat terjadi karena karyawan bagian produksi perusahaan PT Bogasari Surabaya memiliki target kemajuan karier dan standar keberhasilan karier yang lebih tinggi.

\section{Pengaruh OSCD terhadap Career Success yang Dimediasi oleh Career Commitment}

Berdasarkan hasil pada pengujian hipotesis ketujuh menunjukkan hasil bahwa terdapat pengaruh signifikan antara OSCD terhadap career success melalui career commitment. Hal ini menunjukkan bahwa career commitment mempunyai peranan penting dalam memberikan pengaruh OSCD terhadap career success karyawan bagian produksi. Hasil penelitian sebelumnya yang dilakukan oleh (Verbruggen, Sels, \& Forrier, 2007) yang menyatakan bahwa organisasi dapat memberikan pengaruh pada pengalaman karyawan pada kesuksesan karier (baik secara subjektif maupun objektif) dengan mendukung pada pengembangan karier karyawan. Jika dikaitkan dengan perusahaan PT Bogasari Surabaya, dengan adanya program training yang diberikan oleh perusahaan PT Bogasari Surabaya untuk seluruh karyawan khususnya karyawan bagian produksi dalam hal pelatihan, pengembangan dan mentoring pada karyawan dapat meningkatkan komitmen karier dan juga kesuksesan karier karyawan operator bagian produksi di perusahaan.

\section{Pengaruh Career Commitment terhadap Career Success yang Dimoderasi oleh Self Efficacy}

Berdasarkan hasil pada pengujian hipotesis kedelapan menunjukkan hasil bahwa self-efficacy berpengaruh signifikan memoderasi hubungan antara career commitment terhadap career success. Hal ini menunjukkan bahwa selfefficacy mempunyai peranan penting dalam memperkuat hubungan antara career commitment terhadap career success karyawan operator bagian produksi. Penelitian ini mendukung penelitian (Ballout, 2009) menemukan bahwa selfefficacy sebagai variabel intervening memediasi hubungan antara komitmen karier dan subjective career success dan objective career success. Hal ini menunjukkan bahwa karyawan operator bagian produksi PT Bogasari Surabaya memiliki keyakinan individu yang tinggi akan kemampuannya untuk berkomitmen pada karier mereka guna dapat menumbuhkan keberhasilan karier karyawan bagian produksi. 


\section{SIMPULAN}

Penelitian ini berusaha menguji pengaruh proactive personality dan organizational support for career development terhadap career success melalui career commitment yang dimoderasi oleh self-efficacy pada karyawan operator bagian produksi PT Bogasari Surabaya. Berdasarkan hasil uji statistik pada hasil jawaban responden dengan alat uji smartPLS 3.0, maka dapat diambil kesimpulan sebagai berikut.

1. Proactive personality memiliki pengaruh yang positif dan signifikan terhadap career success. Hal ini mengindikasikan bahwa karyawan operator bagian produksi yang memiliki kepribadian proaktif terdorong untuk membuat perbedaan di organisasi (proactive personality), maka sikap karyawan untuk mencapai keberhasilan kariernya (career success) akan semakin tinggi.

2. Organizational support for career development memiliki pengaruh positif dan signifikan terhadap career success. Hal ini mengindikasikan bahwa perusahaan memberikan fasilitas pelatihan dan program training yang dapat mendukung pekerjaan karyawan sehari-hari (OSCD) sehingga dapat meningkatkan kesuksesan karier (career success) karyawan operator bagian produksi tersebut.

3. Proactive personality memiliki pengaruh positif namun tidak signifikan terhadap $c a$ reer commitment. Hal ini mengindikasikan bahwa karyawan operator bagian produksi dalam perkembangan kariernya yang menimbulkan rasa kurang puas atas komitmen karier (career commitment) yang dicapainya. Hal tersebut dikarenakan karyawan operator bagian produksi yang sudah mendekati masa pensiun sedangkan karier yang mereka dapat sampai saat ini masih operator dengan masa kerja yang dibilang bisa cukup lama namun tidak berpengaruh pada kariernya.

4. Organizational support for career development memiliki pengaruh positif dan signifikan terhadap career commitment. Hal ini mengindikasikan bahwa perusahaan PT Bogasari Surabaya mendukung karyawan operator bagian produksi untuk mengembangkan pengetahuan dan keterampilan terkait dengan pekerjaan yang dilakukan dengan memberikan pelatihan berupa training (OSCD), sehingga dapat meningkatkan komitmen karier (career commitment) karyawan bagian produksi tersebut.

5. Career commitment memiliki pengaruh yang positif dan signifikan terhadap career success. Hal ini mengindikasikan bahwa karyawan operator bagian produksi berkeinginan untuk bertahan di pekerjaannya dan bersedia menghabiskan banyak waktu untuk mengembangkan keterampilan pada karier di pekerjaannya (career commitment) sehingga dapat memicu kesuksesan karier yang lebih besar (career success).

6. Proactive personality memiliki pengaruh yang positif namun tidak signifikan terhadap career commitment dan career success. Berarti bahwa career commitment tidak memediasi hubungan antara proactive personality terhadap career success. Hal ini mengindikasikan bahwa karyawan operator bagian produksi yang memiliki kepribadian proaktif dan berkomitmen terhadap kariernya (career commitment) akan memberikan dampak terhadap keberhasilan jenjang kariernya yang lebih tinggi (career success). Namun hubungan mediasi antara kedua hal ini belum signifikan, hal tersebut dikarenakan mereka kesulitan untuk mendapatkan promosi jabatan ke jenjang karier yang lebih tinggi. 
7. Organizational support for career development memiliki pengaruh positif dan signifikan terhadap career commitment dan career success. Berarti bahwa career commitment memediasi hubungan antara Organizational support for career development terhadap career success. Hal ini mengindikasikan perusahaan PT Bogasari Surabaya dapat mendukung dan memotivasi pengembangan diri karyawan operator bagian produksi dalam mencapai keberhasilan kariernya dengan memberikan kesempatan mereka untuk mengembangkan keterampilan dan menetapkan tujuan kariernya (OSCD) sehingga mereka berkomitmen pada kariernya (career commitment) guna meraih pencapaian kesuksesan karier ( $c a$ reer success) karyawan bagian produksi tersebut.

8. Career commitment memiliki pengaruh yang positif dan signifikan terhadap career success yang dimoderasi oleh self-efficacy. Berarti bahwa self-efficacy memperkuat hubungan antara career commitment terhadap career success. Hal ini mengindikasikan bahwa karyawan operator bagian produksi yang memiliki self-efficacy mempunyai keyakinan untuk menetapkan tujuan kariernya (career commitment), sehingga mereka mendapatkan kesuksesan karier di organisasinya.

\section{SIMPULAN PENELITIAN}

1. Career success merupakan hal yang penting bagi karyawan dan pihak perusahaan harus memperhatikan. Dalam hal tersebut, PT Bogasari Surabaya sebaiknya memberikan fasilitas pada karyawan operator khususnya di bagian produksi untuk meningkatkan kemampuannya yang dapat mendukung pekerjaan keseharian karyawan tersebut.
2. Peran dukungan organisasi merupakan hal yang penting bagi karyawan untuk pengembangan pengetahuan dan keterampilan mereka. Dalam hal ini, PT Bogasari Surabaya sebaiknya memberikan pelatihan secara berkala pada karyawan operator khususnya di bagian produksi untuk meningkatkan pengetahuan dan keterampilan yang dapat mendukung pekerjaan keseharian karyawan tersebut dan memberikan program-program training terkait dengan teknologi alat operasional produksi, agar mereka dapat bekerja sebaik mungkin.

3. Karena menetapkan tujuan yang jelas dianggap sebagai elemen penting dari perencanaan karier dan kemungkinan menimbulkan keinginan seseorang untuk menetapkan kemajuan kariernya. Dalam hal ini, perusahaan PT Bogasari Surabaya sebaiknya mendukung sikap ini dengan meningkatkan kompetensi maupun memberikan kesempatan peningkatan job grade pada karyawan operator bagian produksi, sebagai salah satu cara untuk mendukung perencanaan karier dan kemajuan karier mereka.

\section{DAFTAR RUJUKAN}

Arora, R. \& Rangnekar, S. 2016. The Interactive Effects of Conscientiousness and Agreeableness on Career Commitment. Journal of Employment Counseling, 53(1), 14-29. https://doi.org/10.1002/joec.12025.

Ballout, H. I. 2009. Career commitment and Career Success: Moderating Role of SelfEfficacy. Career Development International, 14(7), 655-670. https://doi.org/10. 1108/13620430911005708.

Bateman, T.S. \& Crant, J.M. 1993. The Proactive Component of Organizational-Be- 
havior - a Measure and Correlates. Journal of Organizational Behavior, 14(2), 103118. https://doi.org/10.1002/job.4030140 202.

Blau, G. 1988. Further Exploring the Meaning and Measurement of Career Commitment. Journal of Vocational Behavior, 32, 284297.

Colarelli, S.M. \& Bishop, R.C. 1990. Career Commitment: Functions, Correlates, and Management. Group \& Organization Management, 15(2), 158-176. https://doi.org/ 10.1177/105960119001500203.

Day, R. \& Allen, T.D. 2004. The Relationship between Career Motivation and Self-Efficacy with Protégé Career Success. Journal of Vocational Behavior, 64(1), 72-91. https://doi.org/10.1016/S0001-8791(03) 00036-8.

Hall, D. 1989. Testing the Generalizability of a Career Commitment Measure and Its Impact on Employee Turnover, 103, 88-103.

Judge, T.A., Higgins, C.A., Thoresen, C.J., \& Barrick, M.R.M.R. 1999. The Big Five Personality Traits, General Mental Ability, and Career Success across the Life Span. Personnel Psychology, 52(1), 621-652. https://doi.org/10.1111/j.1744-6570.1999. tb00174.x.
Kong, H., Cheung, C., \& Song, H. 2012. From Hotel Career Management to Employees' Career Satisfaction: The Mediating Effect of Career Competency. International Journal of Hospitality Management, 31(1), 76-85. https://doi.org/10.1016/j.ijhm.2011. 03.002 .

Orpen, C. \& Orpen, C. 2005. The Effects of Organizational and Individual Career Management on Career Success.

Seibert, S.E., Crant, J.M., \& Kraimer, M.L. 1999. Proactive Personality and Career Success. Journal of Applied Psychology, 84(3), 416-427. https://doi.org/10.1037// 0021-9010.84.3.416

Sturges, J., Guest, D., Conway, N., \& Mackenzie Davey, K. 2002. A Longitudinal Study of the Relationship between Career Management and Organizational Commitment among Graduates in the First Ten Years at Work, 748(May), 731-748. Retrieved from http://oro.open.ac.uk/1544/.

Verbruggen, M., Sels, L., \& Forrier, A. 2007. Unraveling the Relationship between Organizational Career Management and the Need for External Career Counseling. Journal of Vocational Behavior, 71(1), 6983. https://doi.org/10.1016/j.jvb.2007.03. 003. 